\title{
¿Un matrimonio infeliz? \\ Democracia y violencia política \\ en Colombia: entre la restricción, \\ cooptación y construcción*
}

\section{An Unhappy Marriage? Democracy and Political Violence in Colombia: Between Restriction, Co-Option and Construction}

\author{
Juan Federico Pino Uribe**
}

Recibido: 8 de septiembre de 2016

Aprobado: 9 de diciembre 2016

Publicado en línea: 10 de octubre de 2017

\section{Resumen}

Este artículo tiene dos objetivos: primero, elaborar una revisión de literatura de las investigaciones que han analizado la "convivencia" entre una democracia electoral relativamente funcional y un conflicto de alta intensidad en Colombia; segundo, a partir de esta revisión, se comparan y discuten algunos de los supuestos conceptuales, estrategias metodológicas y resultados que han tenido estas investigaciones. Como resultado de la revisión, se identifica que la producción académica de la relación entre democracia y violencia se puede organizar en tres tendencias analíticas. La primera estudia las formas en que una democracia restringida motivó el surgimiento de la violencia política, mientras que la segunda analiza cómo la violencia

\section{Abstract}

This article has two objectives. First, to structure a literature review of the research that has analyzed the "coexistence" between a relatively functional electoral democracy and a high intensity conflict in Colombia. Secondly, from this review, some of the conceptual assumptions, methodological strategies and results from these investigations are compared and discussed. From this review, it is identified that the academic production about the relationship between democracy and violence can be organized into three analytical tendencies. The first one studies the ways in which a restricted democracy motivates the emergence of political violence; on the contrary, the second one analyzes how political violence negatively affects democracy, the latest

doi:10.11144/Javeriana.papo22-2.midv

\footnotetext{
* Artículo de revisión. Agradezco los comentarios realizados por Johanna Amaya Panche a versiones preliminares de este artículo y las críticas y modificaciones sugeridas por los pares evaluadores que permitieron mejorarlo.

** Politólogo por la Pontificia Universidad Javeriana, magíster en Ciencia Política por la Universidad de los Andes y doctorando en Ciencia Política de la misma universidad. Correo electrónico: jf.pino31@uniandes.edu.co y https:// www.researchgate.net/profile/Juan_Pino_Uribe ORCID: http://orcid.org/0000-0003-0799-3001
} 
política incide negativamente en la democracia y la última tendencia se centra en entender esta relación como un proceso de larga duración que está articulado a los procesos de construcción del Estado colombiano. En la última parte del artículo, se comparan las diferencias conceptuales y metodológicas de las tres tendencias. A pesar de sus diferencias, se concluye que las tres coinciden en la forma en que la democracia ha influido en el comportamiento estratégico de guerrillas y paramilitares y estos, a su vez, han causado transformaciones formales e informales que han alterado y amenazado el funcionamiento de las instituciones democráticas en el ámbito local, regional y nacional.

\section{Palabras clave}

violencia política; democracia; política subnacional; actores armados; democracia; posconflicto

\section{Cómo citar este artículo:}

Pino, J. F. (2017). ¿Un matrimonio infeliz? Democracia y violencia política en Colombia: entre la restricción, cooptación y construcción. Papel Político, 22(2), 369-393. https://doi. org/10.11144/Javeriana.papo22-2.midv trend being focused on understanding this relationship as a long-term process linked to the construction processes of the Colombian State. In the last part of the article, the conceptual and methodological differences of the three tendencies are compared. Despite their differences, it is concluded that the three coincide in the way in which democracy has influenced the strategic behavior of the armed actors and how they have caused formal and informal transformations that have threatened or co-opted democratic institutions.

\section{Keywords}

political violence; democracy; subnational politics; armor actors; democracy; postconflict 


\section{Introducción}

Los acuerdos de paz de La Habana firmados por las Fuerzas Armadas Revolucionarias de Colombia (FARC) y el Gobierno nacional en cabeza del presidente Juan Manuel Santos el 24 de noviembre de 2016 han sido objeto de diversas polémicas en Colombia. Una de estas ha sido su participación en política, bajo el argumento de que una apertura e inclusión le permitiría "cambiar las armas por votos" (El País, 2013). Los límites de esta inclusión, la naturaleza de su participación y la capacidad del Estado para lograr la reintegración y participación política de los guerrilleros han sido algunos de los puntos que mayor discusión han generado en la sociedad y se han constituido en una de las críticas más fuertes al acuerdo de paz por parte de sectores políticos que se opusieron a las negociaciones de paz realizadas en La Habana (Losada y Liendo, 2016; Cruz, 2015; Montoya, 2014).

La inclusión política de las FARC y la apertura a la participación de nuevos sectores producto de las negociaciones y posteriormente de los acuerdos de paz de La Habana hacen pertinente analizar la forma en que la democracia y la violencia política han sido dos fenómenos que se han desarrollado conjuntamente en los últimos sesenta años. Esta relación ha sido característica de Colombia, que ha tenido uno de los conflictos armados internos de mayor duración en el mundo (Nasi, 2007) y una de las democracias más estables en la región (Pécaut, 2001a). Según esto, los objetivos de esta revisión de literatura son clasificar y exponer las diferentes miradas analíticas que se han utilizado para analizar la coexistencia entre la institucionalidad democrática y la violencia política en el ámbito local, regional y nacional.

En la literatura revisada, se identificaron tres perspectivas en los estudios sobre democracia y violencia: en la primera, se analizan y reseñan los trabajos que expusieron que el carácter cerrado y restringido del régimen político era el principal promotor del conflicto armado y la violencia política; en la segunda, se describe cómo después de las reformas de apertura política de la Constitución de 1991 distintos estudiosos invierten la relación descrita y analizan la forma en que el conflicto armado afecta diferentes componentes del sistema político y la democracia electoral colombiana; y en la tercera, se identifica una serie de estudios que analizan la interacción entre violencia y los procesos de formación del Estado colombiano.

Esta diferenciación y desarrollo de los estudios sobre democracia y violencia está articulada no solo a los intereses académicos de los investigadores, sino a los profundos cambios que ha experimentado el conflicto colombiano en las últimas décadas del siglo XX y en la primera década del siglo XXI. El artículo está organizado de la siguiente forma: primero, se exponen las diferentes perspectivas desde las cuales se ha estudiado la relación entre democracia y violencia política; segundo, se analizan las similitudes, diferencias y ventajas que tienen las distintas investigaciones para entender la coexistencia de la violencia política, democracia e institucionalidad democrática; y por último, se 
concluye que democracia y violencia política en Colombia son dos procesos que se han influido mutuamente y causado transformaciones formales e informales en las instituciones democráticas y en el comportamiento estratégico de guerrillas y paramilitares en el conflicto armado colombiano.

\section{De la democracia restringida a la democracia asediada}

Restringida fue el adjetivo por excelencia que utilizaron académicos y políticos para designar la democracia colombiana (Pizarro, 1989; Bejarano y Pizarro, 2002). Esta restricción de la participación política ${ }^{1}$ de fuerzas diferentes del Partido Liberal y del Partido Conservador fue un factor relevante para explicar el surgimiento de diferentes grupos armados, especialmente del M-19, y la continua presencia de las FARC y del Ejército de Liberación Nacional (ELN), entre otros. Según la Comisión de Estudios sobre la Violencia (1987), "las guerrillas aparecían en Colombia como uno de los instrumentos obligados y a veces legitimados por algunas capas de la población para expresar sus demandas y expectativas ante un sistema cerrado" (p. 46).

En este sentido, estas investigaciones se centraban más en los aspectos formales del régimen, que, desde la perspectiva de los investigadores, incentivaban la violencia política, como la restricción a la participación política. Otros estudios ligaban este factor con aspectos como la pobreza e inequidad de la sociedad colombiana, producto de la falta de respuesta del Estado a las necesidades de un país que se estaba modernizando y urbanizándose rápidamente (Sánchez, 1991).

Esta necesidad de entender las causas y dinámicas de la violencia política se incrementó por el fortalecimiento de guerrillas y paramilitares y el desafío directo al Estado colombiano por parte del narcotráfico protagonizado por el cartel de Medellín y Cali (Camacho, 1999; Dávila, 2002). En este contexto, expresiones como la desinstitucionalización (Pizarro, 1989) o la crisis política colombiana (Leal y Dávila, 1991) llamaron la atención sobre cómo fenómenos como el predominio bipartidista, la incapacidad del sistema político de incluir nuevas fuerzas sociales y el clientelismo estaban minando la legitimidad del Estado colombiano y sus instituciones (Leal, 2010). Las características institucionales del régimen desde estas perspectivas incidían en un fortalecimiento de los actores violentos, y diversos analistas llegaron a la conclusión de que la principal solución para la violencia política era "profundizar la democracia como antídoto de la violencia” (Comisión de Estudios sobre la Violencia, 1987, p. 27).

\footnotetext{
${ }^{1}$ El carácter restringido del régimen político ha sido cuestionado por diferentes estudios que demuestran que, al contrario de lo que se afirmaba, durante el Frente Nacional se fortalecieron movimientos de oposición al bipartidismo, de los cuales los más importantes fueron el Movimiento de Renovación Liberal y la Alianza Nacional Popular (Hartlyn 1993; Gutiérrez, 2007).
} 
En este contexto, los procesos de descentralización y la apertura democrática, que se dieron con las reformas de 1986 y la Constitución de 1991, siguieron varios de los análisis y diagnósticos que se habían realizado para explicar el conflicto armado, sin embargo, no tuvieron un efecto significativo sobre su intensidad y crecimiento (Ortega y Echeverry, 2012; Bejarano y Pizarro, 2002). Si bien se presentó la desmovilización e inclusión en la política de diferentes grupos guerrilleros a la vida nacional, las FARC y el ELN siguieron activos y se registró un acelerado crecimiento de los grupos paramilitares (Dávila, 2002).

En este sentido, las políticas de apertura del régimen lograron que el sistema político colombiano no fuera considerado como restringido; sin embargo, también evidenciaron que la relación entre exclusión y violencia no era tan clara, como se había sostenido en la década de 1980 desde la academia y algunos sectores el Estado nacional. La apertura política y las reformas de descentralización no terminaron con la violencia política, sino que esta se incrementó y el impacto de este tipo de violencia en el sistema político comenzó a ser visto como una amenaza central para el funcionamiento de la democracia.

Así las cosas, diferentes analistas (Archer, 1995; Kline, 1995; Bejarano y Pizarro, 2002) expusieron que la coacción de los derechos civiles, las amenazas al proceso electoral y la consolidación de órdenes sociales diferentes del Estado, no solo entorpecían el funcionamiento del sistema político, sino que ponían en peligro la institucionalidad democrática. En ese sentido, se consideró que la democracia colombiana estaba bajo asedio y ataque por parte de actores informales que, a causa de la debilidad del Estado, reconfiguraban y afectaban el régimen político. Estas investigaciones, si bien pusieron en el centro del debate el impacto de la violencia en el sistema político, y cambiaron la perspectiva desde la cual se analizaba el conflicto armado, no explicitan muy bien los mecanismos que los actores armados utilizan para relacionarse con el sistema político, cuáles son sus intenciones o si existe un comportamiento diferenciado entre estos en su accionar frente al sistema político democrático.

\section{Entre la incidencia y la cooptación}

Esta preocupación por la relación entre democracia y violencia conllevó a diferentes investigadores a estudiar en qué formas incidía la violencia política, más concretamente los actores armados, en el juego democrático. Por consiguiente, estas investigaciones se realizaron en un contexto diferente de los estudios sobre violencia de la década de 1980, que es necesario aclarar. Estos cambios, no solo se centraron en la institucionalidad estatal y en el régimen político, sino en la creciente capacidad armada y territorial de los actores armados. En este apartado, se explica qué tipo de cambios institucionales afectaron la dinámica del conflicto, cómo cambiaron los actores y armados y cuáles son las tendencias que estudiaron la relación entre violencia y democracia en este nuevo contexto. 
Los procesos de descentralización debilitaron los lazos de coordinación entre la clase política local, regional y nacional que se habían forjado durante el Frente Nacional. Como lo expone Gutiérrez (2007), existía una serie de mecanismos de coordinación entre el Ejecutivo y el Congreso para componer la estructura política del país, que se basaba en el poder que tenía el presidente de nombrar gobernadores y estos a los alcaldes; en ese sentido, los congresistas, según su poder electoral, influían en los nombramientos. Una segunda característica era que el presupuesto regional y local estaba centralizado en el Ejecutivo, por lo cual la asignación de recursos dependía del Estado nacional (Dávila, 2002). Con las reformas de descentralización de 1986 y la Constitución de 1991, se presentan varios cambios significativos en los distintos niveles territoriales del Estado colombiano (Falleti, 2010; Restrepo, 2015). En primer lugar, la elección popular de alcaldes (1986) y gobernadores (1991) trajo como consecuencia "que los baronatos empezaran a deshacerse" (Gutiérrez, 2007, p. 259). Asimismo, la descentralización económica incidió en que mientras aumentaba el poder político de los dirigentes locales y regionales estos tuvieran mayor presupuesto y autonomía en su manejo (Sánchez y Chacón, 2005, p. 4), un fraccionamiento de las fuerzas políticas y un aumento de la competencia política en el ámbito local y regional (Milanese, Abadía y Manfredi, 2016; Pino, 2017).

Además de los cambios institucionales, los actores armados presentaban significativas diferencias y transformaciones. En primer lugar, las FARC y el ELN, que habían estado confinados a las zonas de colonización y eran un actor relativamente periférico en el país en las décadas de 1960 y 1980 (Pizarro, 1991), habían experimentado un crecimiento significativo en número de hombres, capacidad logística y armada (Peñate, 1999; Pizarro, 2006). Esto les había permitido extender su presencia a regiones que estaban más integradas a los circuitos de la economía nacional y donde el Estado era más fuerte (Echandía, 1999). Los paramilitares, por su lado, también se habían fortalecido; si bien en un principio estaban confinados a ciertas regiones en la década de 1980, en la década de 1990, estos se comenzaron a expandir a regiones que tradicionalmente habían estado controladas por la guerrilla, además consiguieron articular cierta coordinación entre los diferentes grupos por medio de la creación de las Autodefensas Unidas de Colombia (AUC), un intento de confederar los distintos grupos paramilitares que habían ido surgiendo en el país (Duncan, 2007).

Es en este contexto de cambio y transformación donde la capacidad y los incentivos para que los actores armados intervinieran en los diferentes niveles territoriales del régimen democrático es que surge lo que se puede denominar la segunda corriente de estudios sobre la violencia política, la cual se puede dividir en dos tendencias. Los estudios de la primera tendencia se centraron en identificar y analizar los efectos de los actores armados sobre los distintos elementos del sistema político que integran la dimensión electoral de la democracia, esto es, las elecciones y las preferencias electorales 
de los ciudadanos. Mientras que las investigaciones en la segunda tendencia se enfocaron en observar los procesos de cooptación de la institucionalidad estatal en diferentes ramas del poder público y analizar las motivaciones detrás de este intento de cooptación.

La apertura de los espacios políticos de participación electoral, elección de alcaldes y gobernadores permitió que diferentes investigadores se interrogaran sobre las estrategias que los actores armados utilizaban en sus zonas de influencia y en las áreas de disputa para afectar el proceso electoral. En la primera tendencia, se pueden encontrar estudios que, en general, aunque no exclusivamente, usan herramientas estadísticas para analizar el impacto de la violencia en la democracia. Uno de los primeros análisis de esta relación es la investigación de García y Hoskin (2003), quienes encuentran una relación significativa entre la baja participación electoral y la presencia guerrillera. Estos hallazgos son ratificados por otras investigaciones que encuentran que la presencia de la guerrilla y el Ejército tiene una asociación negativa con la participación electoral de los ciudadanos (Ceballos, 2005).

Además, esta serie de investigaciones también permitió precisar que las preferencias estratégicas de los actores armados tienen implicaciones en el tipo de influencia que estos intentan ejercer sobre el proceso electoral. Así las cosas, se pudo evidenciar que actores como la guerrilla tienden a sabotear el proceso electoral en sus zonas de influencia, lo cual afecta la participación electoral y hace que esta disminuya, mientras que en zonas paramilitares la votación por los candidatos tradicionales aumenta (García, 2007; 2009). Hoyos (2009) reafirma este hallazgo, pero expone que la influencia de un grupo sobre el proceso electoral no solo depende del tipo de grupo del tipo y nivel de control de la zona, sino que encuentra que no en todos los casos el accionar de los paramilitares presenta un mismo patrón, independiente su nivel de control, sobre la participación y competencia política, sino que este es diferenciado regionalmente y localmente. Por su parte, Gómez-Albarello y Rodríguez-Raga (2007, pp. 74-75) identifican una significativa relación entre presencia de grupos armados y baja competencia electoral en las elecciones para el Senado. Finalmente, Higuera (2017), utilizando una aproximación cuasiexperimental, demuestra que durante la zona de distensión en el Gobierno del presidente Andrés Pastrana (1998-2002) la hegemonía de los partidos políticos tradicionales (Partido Liberal y Partido Conservador), contrario a lo que intuitivamente se podría suponer, aumentó a pesar del control guerrillero de la zona.

La segunda tendencia se centra en otra faceta relevante de la democracia: la institucionalidad estatal. Estas investigaciones tratan sobre una diversidad de temas que tienen como característica común estudiar cómo los actores armados afectan al Estado, o bien por medio de la cooptación por la fuerza, o bien recurriendo a alianzas con diferentes fuerzas políticas. En este sentido, los repertorios para lograr la cooptación de la institucionalidad estatal son diversos y van desde las presiones electorales hasta la creación de órdenes alternativos. 
La apertura democrática subnacional y la creación de nuevas fuerzas políticas incrementó la incertidumbre de los políticos regionales y locales para ganar las elecciones (Gutiérrez, 2007) y creó, inesperadamente, una ventana de oportunidad para que diferentes grupos armados entraran a desempeñar un papel importante en la política local. Una de las estrategias fue intervenir en algunas regiones en los arreglos clientelistas, con los cuales los políticos aseguraban su elección.

En esta tendencia, varias investigaciones analizaron en qué medida los nuevos recursos económicos incentivaban a los actores a ejercer control sobre los candidatos a las alcaldías y los alcaldes electos. Al respecto, Sánchez y Chacón (2005) encuentran que "los grupos armados ilegales asesinaron un total de 70 candidatos a alcaldías, 92 a concejos y 14 a otros tipos de cargos públicos, siendo 1997 el año más crítico con 57 candidatos asesinados, 100 secuestrados y 369 retirados de la contienda electoral por presión de los actores armados" (p. 19). Además, señalan que su accionar y la expansión fue motivado por el interés de capturar los nuevos recursos que el Estado nacional transfería a los municipios y departamentos.

En este contexto, los grupos armados creaban un incentivo significativo por medio de la violencia para que los clientes cumplieran sus acuerdos con los políticos locales (Dávila y Salgado, 2002; Eaton, 2006), al tiempo que neutralizaban la competencia política mediante la eliminación de rivales. En una segunda modalidad, los grupos armados, aprovechando la vulnerabilidad de los gobiernos locales, se apropiaban de los bienes públicos por medio de amenazas o cooptación (Rangel, 1997; Rangel, Borrero y Ramírez, 2004). A estas modalidades de intervenir en la política dichos autores les dieron el nombre de clientelismo armado, que daba cuenta de la forma en que los actores armados se relacionaban con los políticos y los electores para fortalecer sus finanzas y ganar control territorial.

En esta misma línea, distintos estudios econométricos comenzaron a criticar el uso de la pobreza y la exclusión política para explicar la violencia política, y demostraron cómo algunas de las zonas con más recursos del país también eran las más violentas (Deas y Daza, 1995) al convertirse en regiones atractivas, donde los actores armados podían obtener ganancias, apropiándose de los recursos públicos, extorsionando al sector privado o beneficiándose económicamente del narcotráfico (Rubio, 1998, 2004). Estos hallazgos hicieron que en distintas investigaciones se cuestionara la distinción entre delito común y delito político y las causas objetivas y subjetivas para explicar la violencia política, exponiendo que esta no se diferenciaba de la delincuencia común (Rubio, 1998, 2002). Tales ideas entrarían a soportar la postura política que en Colombia no había un conflicto armado, sino más bien una amenaza delincuencial y terrorista que era necesario controlar fortaleciendo el aparato judicial para reducir la impunidad y privilegiando la acción militar (Díaz, 2006). Por lo cual, las distintas investigaciones comenzaron a analizar la violencia política más como un tema de criminalidad y codicia que producto 
de reivindicaciones sociales o exclusión política (Norza, Peñalosa y Rodríguez, 2017; Norza y Espino, 2011; Rubio, 1998).

Sin embargo, esta comprensión de la relación entre violencia política y democracia, como una relación exclusivamente parasitaria y rentística (Rubio, 1998, 2002), fue criticada, en primer lugar, por la forma en que invisibilizaba las relaciones diferenciadas que se establecían entre actores armados, empresas privadas y democracia. En este sentido, varios investigadores problematizaron la relación entre actores y armados y recursos exponiendo que no siempre la relación era de explotación y rentística, sino que esta presentaba variaciones de acuerdo con el tipo de actividad productiva, tamaño de la empresa, características regionales, entre otras variables (Leiteritz, Nasi y Rettberg, 2009; Rettberg, Leiteritz y Nasi, 2010; Rettberg y Ortiz, 2014) y mostraron la importancia de la participación de algunas empresas en el posconflicto (Jiménez, 2014). De igual forma, se subrayó que la distinción entre violencia política y delincuencial no era tan clara, ni analítica ni empíricamente, ya que, según autores como Kalyvas y Arjona, los conflictos armados en Colombia y en otros países no se movían de forma binaria entre lo delincuencial y lo político, sino en una hibridación constante entre estas dos dimensiones, donde lo delincuencial en varias ocasiones se transformaba en herramientas para la consecución de fines políticos (Kalyvas, 2004; Gutiérrez, 2004; Nasi y Rettberg, 2005; Arjona y Kalyvas, 2012).

En segundo lugar, porque la cooptación de la institucionalidad local y regional, no solo se hacía con fines rentísticos, sino también se realizaba por estrategia militar para controlar el territorio. En el caso de las guerrillas, que habían estado confinadas a las zonas de colonización, este proceso significaba entrar a disputar al Estado zonas que tradicionalmente este había controlado, por lo cual, además del interés financiero, el proceso de expansión obedecía al proyecto político de cooptar los espacios institucionales creados por las reformas de democratización (Rangel, 1997; Echandía, 1999; Velásquez, 2009). Especialmente donde la institucionalidad estatal era más débil (Barrero, 2016) y había menos confianza en las instituciones estatales (Palacios, 2016).

Además de las alianzas pragmáticas o el uso táctico de la violencia, también fueron analizadas otra serie de relaciones en torno, por ejemplo, a la construcción de proyectos de dominación de territorios entre políticos y actores armados. Esta relación es evidenciada por Romero (2003, 2007), Corporación Nuevo Arco Iris (2007), López (2010) y Carroll (2011) que exponen que el proceso de descentralización y democratización impulsado por el Estado nacional puso en juego los intereses de las élites políticas y económicas de ciertas regiones, lo cual generó que se hicieran pactos entre estas con grupos paramilitares y sectores del Ejército para conservar los equilibrios de poder locales y regionales. En este caso, más que un interés económico, la cooptación de la institucionalidad obedece también a fines políticos y estratégicos de grupos paramilitares o guerrilleros que fueron relativamente exitosos en ciertas regiones, para excluir o 
eliminar a fuerzas políticas antagónicas e imponer órdenes sociales locales y regionales distintos del nacional (Duddley, 2008; López, 2010; Arjona, 2016).

En esta misma línea, a partir del crecimiento de los grupos paramilitares y su infiltración en la política desde el sector no gubernamental, se han realizado distintas investigaciones que han usado el concepto de autoritarismo subnacional para sostener que estos grupos se aliaron con élites regionales a fin de controlar las regiones por medio de prácticas que incidían en la calidad de la democracia local y regional (Romero, Valencia y Alonso, 2007; Valencia 2009; Velasco y Ávila, 2013; Eaton y Prieto, 2017). Ávila (2010, 2012) expone que en Colombia se han configurado Estados de facto, por lo cual más que autoritarismos se puede hablar de dictaduras que han formado especialmente los grupos paramilitares en alianza con políticos regionales y en que los congresistas pertenecientes a la parapolítica desempeñaron un papel crucial como vínculos entre los distintos niveles de gobierno.

Otros autores han expuesto que el proceso de cooptación institucional no solo acaba en la influencia o en alianzas, sino que se convierte en procesos de captura de las instituciones y reconfiguración de las instituciones locales, regionales y nacionales para proteger estos intereses (Garay, 2008). Este proceso culmina con la creación de órdenes alternativos (González, Bolívar y Vázquez, 2003) en ciertas regiones del país que han sido caracterizadas como "órdenes sociales autoritarios" (Camacho, 2009), "contextos totalitarios” (Wills y Rivera, 2009) o “territorios autoritarios” (Duncan, 2009).

Finalmente, también se pueden identificar investigaciones que han subrayado que el énfasis en las motivaciones políticas y económicas de la interacción entre violencia y democracia han incidido en ocultar que la discriminación y la segregación del régimen político continúan siendo variables pertinentes para explicar la violencia política. Al respecto, Franco (2003, 2005), en sus estudios sobre Medellín, expone cómo la exclusión política y la segregación social de los jóvenes en esa ciudad configura un escenario proclive a la generación y el mantenimiento de las prácticas violentas, especialmente hacia la población joven. En este mismo sentido, otros investigadores han señalado la importancia de seguir considerando la inequidad y la falta de oportunidades en el territorio como una variable relevante para explicar la violencia (Angarita, 2003; Braun, 2009), y los intereses económicos de ciertos sectores sociales hegemónicos han configurado distintos tipos de violencia política para mantener sus privilegios sociales (Angarita, 1999, 2013, 2014).

\section{La violencia y los procesos de construcción de Estado}

Finalmente, una tercera etapa ha examinado los procesos de construcción estatal, la violencia y la democracia a diferencia de los estudios analizados. El examen de esta relación no se puede ubicar en un momento histórico determinado, sino a partir de dos coyunturas significativas, el periodo conocido como la Violencia (1946 y 1966) y las últimas décadas 
del siglo XX, cuando el monopolio sobre la violencia fue desafiado y disputado, en algunas ocasiones exitosamente, por actores armados y élites regionales al Estado colombiano.

En esta medida, autores como Pécaut resaltan:

El Estado colombiano difícilmente llega a ser un agente político de constitución de la nación [...] constantemente parece estar atrapado permanentemente en las tormentas de una sociedad civil que se hace sentir, arrastrado por sus divisiones, sometido a sus exigencias. (2001a, p. 30)

Por consiguiente, el Estado vio subordinada su configuración institucional y su capacidad para articular políticas en el ámbito nacional y regional a una serie de fuerzas exógenas que durante todo el siglo XIX se enfrentaron y negociaron entre sí para privilegiar sus diferentes intereses políticos y proyectos regionales o nacionales.

El incipiente y débil Estado no se estructuró (Oquist, 1978), desde esta perspectiva, en un actor relativamente autónomo de las fuerzas sociales, sino, al contrario, se configuró como un actor y escenario más de disputa entre los diferentes bandos que competían por el poder nacional, lo cual incidía en que algunos no aceptaran los resultados democráticos y prefirieran utilizar la violencia para posicionar sus intereses políticos. Para ilustrar este planteamiento, el estudio de Valencia (1987) sobre la relación entre las constituciones y los conflictos armados es particularmente útil. El autor resalta que las múltiples constituciones en el siglo XIX no se constituyeron a partir de arreglos nacionales, sino que dependieron de la confrontación de fuerzas entre el Partido Conservador y el Partido Liberal; el bando ganador imponía sus condiciones al vencido. Es necesario subrayar que, si bien las fuerzas estatales tenían un grado de participación en estas confrontaciones, ellas eran protagonizadas, principalmente, por las fuerzas privadas que movilizaban diferentes terratenientes y que escapaban claramente de la autoridad del Estado central.

Este escaso control del Estado sobre las diferentes formas de violencia en la sociedad también ha sido un rasgo reseñado por diferentes autores (Palacios, 1995; Pécaut, 2001b; González et al., 2003). En este sentido, la violencia por fuera del control de la institucionalidad estatal también se ha constituido en un rasgo importante a fin de entender los procesos de resistencia que encuentra la consolidación democrática para expandirse y consolidarse en el territorio nacional (Pino, 2013, 2016; Barrero, 2016). Así, la relación entre democracia y violencia se articula al análisis de los procesos de construcción y, en cierta medida, destrucción del Estado en Colombia.

Entre dichos estudios, está el realizado por Oquist (1978) sobre el colapso parcial del Estado, donde señala que el fortalecimiento del Estado colombiano fue causado por las transformaciones modernizadoras de la sociedad experimentadas en el siglo XX, mientras que su colapso obedeció a las inercias de los procesos políticos y a la violencia 
partidista. Así las cosas, su argumento expone que el Estado experimentó un proceso de fortalecimiento en la primera mitad del siglo XX, impulsado, principalmente, por la necesidad de "acomodar a la sociedad colombiana a las estructuras socioeconómicas capitalistas y acelerar la inserción de Colombia dentro del sistema capitalista mundial” (p. 34).

Paradójicamente, esta fortaleza también creó un incentivo para su destrucción. A pesar de la modernización, los partidos seguían intentado imponer su respectiva hegemonía sobre el otro y, en este contexto, el control de la institucionalidad estatal daría una preeminencia fundamental a cualquiera de los dos bandos. Así es como un proceso de cambio (modernización y ampliación institucional del Estado) y de inercia (naturaleza sectaria de la cultura política partidista) configuraría una dinámica de rivalidad política que, a causa del 9 de abril, escalaría a nivel de un conflicto violento entre los dos partidos tradicionales, lo cual conllevaría el quiebre de las instituciones democráticas y de la legitimidad del Estado (Oquist, 1978). ${ }^{2}$ Desde esta perspectiva, es la democracia y los problemas de alternación política los que condujeron al colapso del Estado.

Esta relación entre debilidad estatal, deficiencia de la democracia y violencia política también ha sido estudiada por Orjuela (2000), quien expone que las deficiencias en la estructuración de control central sobre los actores que poseen el poder regional han incidido en la capacidad de establecer un monopolio de la violencia en el país y que la institucionalidad democrática sea débil respecto de los poderes regionales. Pizarro y Bejarano (2003) retoman el concepto del colapso parcial del Estado (Oquist, 1978), a fin de explicar la imposibilidad del Estado para afrontar el desafío que representaba la guerrilla y los paramilitares a finales del siglo XX y principios del siglo XXI y la construcción de proto-Estados subnacionales por fuera de la institucionalidad democrática.

Estas visiones han sido criticadas por autores como González (2003) quien expone que las dinámicas de la violencia en Colombia y su relación con el Estado pueden ser interpretadas de mejor manera si se abandona la idea de “un Estado monolítico” (p. 136) y, además, plantea que "esta representación [de la ausencia o colapso del Estado] suele perder de vista que el Estado como tal es un conjunto de dinámicas sociales, de juegos azarosos de dominación que no necesariamente cristalizan en la forma de instituciones y organismos estables” (González et al., 2003, p. 248). De esta manera, González et al. exponen que es necesario cuestionar nociones como fracaso o colapso desde una perspectiva sociogenética (Pizarro y Bejarano, 2003). Esta implica entender la construcción del Estado y del régimen democrático en Colombia como procesos de larga duración que han tenido diferentes etapas y características y conllevan una gradual integración de territorios y poblaciones (González et al., 2003). Tal proceso de integración no es

${ }^{2}$ Este derrumbe comprendería la quiebra de las instituciones establecidas, la pérdida de la legitimidad del Estado y el surgimiento de contradicciones dentro del aparato armado del Estado. 
automático, sino que encuentra poblaciones y grupos que se oponen y resisten por medio de la violencia o huyendo a otras regiones que el Estado todavía no ha integrado dentro del territorio nacional (Bolívar, 2010). Desde esta perspectiva, los partidos son un actor estratégico para el Estado, ya que, en un contexto de alta fragmentación social y política, permitieron la integración e inclusión de diferentes sectores sociales y territorios en el país en la medida en que se constituyeron en federaciones laxas de redes locales y regionales que articulaban al Estado las poblaciones por medio de sus clientelas (González, 2003, p. 137). Sin embargo, la geografía y conformación histórica han permitido que algunos sectores de la población evadan la integración por parte del Estado y los partidos a la sociedad y que haya ciertos sectores de la población y el territorio que no se encuentren dentro del dominio estatal.

Así las cosas, en esta línea de investigación, se evidencia que la relación entre democracia y violencia ha sido interpretada de forma diferenciada por los distintos autores que la han estudiado, y no siempre con el mismo sentido causal. Por ejemplo, Oquist expone que, paradójicamente, fue el juego democrático y, en particular, la exacerbación de la competencia sectaria y partidista la que genera violencia e incide en los procesos de destrucción estatal. Mientras que, en las segundas investigaciones, la relación se invierte, y es la falta de capacidad estatal la que facilita que actores armados o élites regionales amenacen la institucionalidad democrática. Finalmente, la última tendencia, que estudia específicamente la presencia diferenciada del Estado, expone que esta relación no es unicausal, sino multicausal y que depende, principalmente, de la forma en que el Estado se extiende territorialmente y de las diferentes lógicas de negociación con las élites políticas subnacionales, que deben ser estudiadas desde una perspectiva histórica de larga duración.

\section{Perspectiva comparada de los estudios sobre la relación entre violencia política y democracia en Colombia}

Los múltiples estudios sobre la relación entre violencia política y el funcionamiento de la democracia demuestran que este tema ha tenido una perenne relevancia dentro de la ciencia política colombiana. Todas las investigaciones coinciden en afirmar que la violencia política afecta la democracia colombiana, constriñendo a los electores, amenazando a los políticos, apoderándose de recursos públicos, cooptando la institucionalidad estatal o incidiendo en los procesos de construcción del Estado, además, detectan que hay un comportamiento diferenciado de los actores armados. Si bien presentan varias similitudes entre sí, la mayoría de las investigaciones constatan que hay divergencias en la forma en que interactúan con la democracia, sus diferentes instituciones y la ciudadanía.

La guerrilla, en general, intenta cooptar o afectar las instituciones democráticas por medio de saboteos y amenazas, mientras que los paramilitares se centran más en alianzas con grupos regionales, en influir sobre el proceso electoral y en desempeñar un 
papel dual, ya que, si bien reivindican un discurso institucional y proestatal, al mismo tiempo lo debilitan al cooptar diversas instituciones, sin abandonar, claro está, el uso de la violencia. La tendencia que se centra en el estudio de la dimensión electoral de la democracia también expone que los impactos de estos grupos en el proceso electoral son diferenciados. En este sentido, en el pasado proceso de paz con los paramilitares, y el que se está llevando a cabo en La Habana con las FARC, es de gran importancia adelantar estudios sobre la forma específica en que nuevos grupos armados, conocidos como los grupos posdesmovilización, se relacionan con las reglas e instituciones de la democracia a nivel subnacional (Corpovisionarios, 2017) y mejorar el acceso a la información sobre sus acciones por parte del Estado nacional (Fernández de Lara Gaitán, 2016) en un contexto de mayor movilización social (Cepeda, 2016).

Otra similitud significativa entre las tres tendencias es la ventana de oportunidades que generó la descentralización política y fiscal para los actores armados y su papel para incidir en la política local. Paradójicamente, a diferencia de los estudios de la década de 1980 que propendían a una apertura del sistema político colombiano como un antídoto para la paz, una conclusión transversal de los diferentes estudios es que la apertura no repercutió en una pacificación del país; al contrario, en algunas regiones, se configuraron escenarios de escalamiento de la violencia política, para excluir rivales políticos, conservar equilibrios regionales o apropiarse de los recursos públicos o privados. Finalmente, las dos primeras tendencias revelan, aunque no en todos los estudios, que una de las principales consecuencias que tiene la violencia política ejercida por los grupos armados es reducir la participación y manipular la participación electoral de los ciudadanos en un contexto de desvanecimiento de la autoridad estatal (Querejazu, 2011).

A pesar de sus similitudes, estas tres corrientes también reflejan importantes diferencias entre sí. Por ejemplo, el foco analítico para estudiar la relación entre violencia y democracia. La primera se centra, principalmente, en las instituciones electorales para ver cómo los actores armados influencian las elecciones políticas. En cambio, la segunda, no solo se centra en las elecciones, sino también considera otras instituciones que componen el Estado. En este sentido, se analizan las acciones de los grupos armados frente a las relaciones de conflicto y cooperación que pueden tener con el poder judicial o sectores de la fuerza pública (Romero, 2007; López, 2010).

Asimismo, su análisis también comprende instituciones informales como el clientelismo (Dávila y Salgado, 2002; Eaton, 2006) y la forma en que estas prácticas informales son reconfiguradas por la relación entre políticos y actores armados. De igual forma, no solo analiza la influencia en el ámbito electoral, sino que también estudia otras facetas de la vida democrática como la libre expresión o los derechos de asociación de las personas que se ven afectados por la violencia política (Carroll, 2011). Al aprehender estos ámbitos, permite ver cómo el accionar de los grupos armados afecta las funciones 
del Estado y cambia no solo el comportamiento político, sino también social de los ciudadanos en las áreas donde estos actores han consolidado su dominio militar y político (Wills y Rivera, 2009; Duncan, 2009). La tercera tendencia permite observar que la relación entre democracia y violencia no es unicausal, sino que depende de procesos históricos a largo plazo y de la forma en que el Estado se va expandiendo territorialmente.

En diferentes estudios, la relación entre democracia y violencia, en la primera tendencia, es confinada principalmente al estudio de tres actores: políticos, actores armados y ciudadanos en un marco institucional claro, el proceso electoral (Ceballos, 2005; García, 2007; Hoyos, 2009). Si bien esta relación es importante, no necesariamente agota el número de actores que participan, obstruyen o hacen posible el funcionamiento de la democracia nacional y subnacional. Así las cosas, la segunda y tercera perspectiva toman en cuenta otros actores sociales significativos en el sistema político y en el funcionamiento de la democracia como las élites regionales (González et al., 2003; Romero, 2007), los gobernantes nacionales (Garay, 2008; López, 2010), las empresas (Rettberg et al., 2010) y actores sociales (Carroll, 2011).

Otra diferencia significativa es la acepción de qué se entiende por violencia en las investigaciones de la segunda tendencia. En los estudios de cooptación del Estado, se puede apreciar una amplia diversidad de acepciones del término; sin embargo, no hay una definición transversal que sea utilizada en los diferentes estudios. Esto puede conllevar que este concepto se estire conceptualmente y entren a ser considerados como violencia política determinados tipos de acciones que no sean estimadas de este modo por otros autores, lo cual puede crear confusión conceptual y analítica (López, 2010; Romero, 2007). En este sentido, se evidencia una fortaleza en los estudios de la dimensión electoral, ya que la mayoría tiene una forma similar de entender violencia política y presencia de los grupos armados en el territorio (García, 2007; García y Hoskin, 2003; Hoyos, 2009). Lo anterior es importante porque estas investigaciones han desarrollado formas de medir empíricamente tales fenómenos, lo cual permite la comparación de resultados y la acumulación de conocimientos sobre esta relación. Esto aplica también a la definición de democracia que acotan y circunscriben al tema electoral, que, si bien no analiza otras facetas del funcionamiento democrático, permite dar cuenta de las transformaciones que se producen a lo largo del país y sacar conclusiones generales de este fenómeno (GómezAlbarello y Rodríguez-Raga, 2007). En este sentido, los estudios han utilizado distintas formas de entender y conceptualizar la violencia política y la democracia, y así existe una definición más procedimental y homogénea de estos dos fenómenos en los estudios de la primera tendencia, mientras que en la segunda y tercera hay más diversidad conceptual para definir violencia política y democracia y un uso más maximalista de ellos.

En este orden de ideas, principalmente por sus diferencias, cada perspectiva analítica tiene diferentes fortalezas y debilidades, pero es necesario hacer énfasis en dos 
debilidades que tienen para analizar el comportamiento de la democracia. En primer lugar, los estudios de cooptación institucional no definen muy bien este fenómeno y, a pesar de los esfuerzos por obsérvalo empíricamente (López, 2010), no explican a fondo en qué momento se presenta la cooptación de la democracia. Lo anterior implica otro problema en la medida que en varios estudios no evidencian con claridad qué actor, en efecto, protagoniza la cooptación; si son los políticos que utilizan los actores armados o son los actores armados quienes emplean a los políticos para cooptar las instituciones democráticas (Gutiérrez, 2010).

En segundo lugar, los estudios de la primera tendencia, al tener una perspectiva más cuantitativa de la violencia política, pueden tener un problema en la forma en que esta se mide, según el número de acciones de los actores armados. Si bien estas, como asesinatos, secuestros, ataques a poblaciones, constituyen un dato relevante para observar áreas en disputa, como lo advierte Kalyvas (2004), en los territorios en que un actor es dominante, la violencia política tiende ser mínima. En este sentido, es necesario preguntarse si centrarse en tal clase de indicadores estaría invisibilizando regiones donde grupos armados han conseguido controlar la violencia política. Más aún en un contexto de posconflicto, donde las fronteras entre lo criminal y lo político se vuelven más difusas, las formas de violencia cambian y se pueden hacer menos visibles. Estos grupos posdesmovilización pueden tener la capacidad para restringir los derechos ciudadanos y afectar la expansión territorial de la democracia en un contexto de posconflicto caracterizado por nuevas formas de violencia política.

\section{Conclusiones}

La inclusión y participación política de las FARC ha suscitado un debate sobre la legitimidad de que un grupo armado deje las armas para entrar a participar en el juego democrático, la forma en cómo lo hace y las condiciones en que el Estado facilita la inclusión política (Quishpe, 2017). Las críticas y los argumentos en favor o en contra de esta participación muestran la importancia de sistematizar los aportes que han realizado distintos académicos para entender la relación entre violencia política y democracia en las últimas décadas. Algunas perspectivas han subrayado el carácter legítimo del derecho a la violencia en contextos de segregación, discriminación e injusticias sociales (Comisión de Estudios sobre la Violencia, 1987; Franco, 2007), mientras que otras han resaltado el carácter criminal y delincuencial de la violencia política y criticado los intentos de legitimación o justificación de estas prácticas violentas (Rubio, 2005).

Como se ha mostrado en esta revisión, tales discusiones académicas utilizan distintos marcos teóricos, conceptuales, información empírica y posturas políticas para aprehender este fenómeno. No obstante, una conclusión común que se desprende de esta literatura es que democracia y violencia política en Colombia son dos procesos que se han influido 
mutuamente y causado transformaciones formales e informales en las instituciones democráticas y en el comportamiento estratégico de guerrillas y paramilitares, lo cual hace patente que el análisis de la relación entre democracia debe trascender una lectura dicotómica entre la justificación o la criminalización de la violencia política y centrarse más bien en su comprensión según las formas en que esta se ha desarrollado y relacionado con las instituciones democráticas a nivel territorial y en distintos momentos históricos de Colombia.

En conclusión, las tres perspectivas para analizar la relación entre la violencia política y el funcionamiento de la democracia revelan un avance significativo para entender esta compleja interacción en un contexto de posconflicto. Estas investigaciones pueden contribuir a la cualificación del debate social y mediático que se ha venido produciendo sobre la participación política de los grupos insurgentes después de su desmovilización y ayudar a dimensionar los riesgos y retos que afronta la inclusión política de estos actores y la apertura del sistema democrático en Colombia.

\section{Referencias}

Angarita Cañas, P. E. (1999). ¿Son los paramilitares actores políticos? Vademécum, 2, 40-65.

Angarita Cañas, P. E. (2003). Conflictos, guerra y violencia urbana: interpretaciones problemáticas. Nómadas, 19, 96-104.

Angarita Cañas, P. E. (2013). Propuestas de seguridad desde organizaciones de base en contextos violentos. En A. Abello y P. Angarita (eds.), Nuevo pensamiento sobre seguridad en América Latina: hacia la seguridad como un valor democrático (pp. 107-130). Medellín: Consejo Latinoamericano de Ciencias Sociales.

Angarita Cañas, P. E. (2014). Políticas para enfrentar la violencia y la inseguridad en Colombia. Cuestiones de Sociología, 10. Recuperado de http://www.cuestionessociologia.fahce.unlp.edu.ar/article/view/CSn10ao8

Archer, R. (1995). Party strength and weakness in Colombia's besieged democracy. En S. Mainwaring y T. R. Scully (eds.), Building democratic institutions: Party systems in Latin America (pp. 164-199). Palo Alto, CA: Stanford University Press.

Arjona, A. M. (2016). Rebelocracy: Social order in the colombian civil war. Nueva York: Cambridge University Press.

Arjona, A. M. y Kalyvas, S. N. (2012). Recruitment into armed groups in Colombia: A survey of demobilized fighters. En Y. Guichaoua (ed.), Understanding collective political violence (pp. 143-171). Londres: Palgrave Macmillan.

Ávila Martínez, A. F. (2010). Injerencia política de los grupos armados ilegales. En C. López Hernández (ed.), Y refundaron la patria... de cómo mafiosos y políticos reconfiguraron el Estado colombiano (pp. 79-213). Bogotá: Debate. 
Ávila Martínez, A. F. (2012). Poder local: estructuras políticas y crimen en Colombia. Bogotá: Friedrich-Ebert-Stiftung. Recuperado de http://library.fes.de/pdf-files/ bueros/kolumbien/o9886.pdf

Ávila Martínez, A. F. y Velasco M., J. D. (2013). Democracias en venta: partidos, corrupción electoral, violencia y crimen en Colombia (2007-2011). Bogotá: Corporación Nuevo Arco Iris.

Barrero, F. (ed.) (2016). Elecciones regionales 2015: los retos de un país en camino hacia la paz. Bogotá: Fundación Konrad Adenauer.

Bejarano, A. M. y Pizarro Leongómez, E. (2002). From "restricted" to "besieged": The changing nature of the limits to democracy in Colombia. Working Paper, 296.

Bejarano, A. M. y Segura Bonnett, R. (1996). El fortalecimiento selectivo del Estado durante el Frente Nacional. Controversia, 169, 10-35.

Bolívar, I. (2010). Sociedad y Estado: la configuración del monopolio de la violencia. En L. J. Orjuela E. (comp.), El Estado en Colombia (pp. 263-305). Bogotá: Universidad de los Andes.

Braun, N.-C. (2009). Displacing, returning, and pilgrimaging: The construction of social orders of violence and non-violence in Colombia. Civil Wars, 11(4), 455-476. https://doi.org/10.1080/13698240903403832

Camacho, Á. (1999). Narcotráfico y paz: alternativas políticas. En Á. Camacho Guizado y F. Leal Buitrago (comps.), Armar la paz es desarmar la guerra: herramientas para lograr la paz (pp. 263-298). Bogotá: Universidad Nacional de Colombia.

Camacho, Á. (2009). Paranarcos y narcoparas: trayectorias delincuenciales y políticas. En Á. Camacho, G. Duncan, C. Steiner, R. Vargas y M. E. Wills (eds.), A la sombra de la guerra: ilegalidad y nuevos órdenes regionales en Colombia (pp. 7-97). Bogotá: Universidad de los Andes.

Camacho, Á., Duncan, G., Steiner, C., Vargas, R. y Wills, M. E. (eds.) (2009). A la sombra de la guerra: ilegalidad y nuevos órdenes regionales en Colombia. Bogotá: Universidad de los Andes.

Carmona, S. y Jaramillo, P. (2015). Números, conmensuración y gobernanza en los estudios de impacto ambiental. Revista Iberoamericana de Ciencia Tecnología y Sociedad, 10(30), 61-79.

Carroll, L. A. (2011). Violent democratization: Social movements, elites, and politics in Colombia's rural war zones, 1984-20o8. Notre Dame: University of Notre Dame Press. 
Ceballos, M. (2005). El país detrás de las urnas: impacto de la reforma política en contextos de crisis humanitaria. Documento de Trabajo, 74.

Cepeda, C. C. (2016). ¿Dónde están y quiénes son los que protestan contra la globalización? Caracterización de las organizaciones participantes en el Foro Social Mundial 2001, 2004 y 2008. Papel Político, 21(2), 505-536.

Comisión de Estudios sobre la Violencia (1987). Colombia: violencia y democracia. Bogotá: Universidad Nacional de Colombia

Corporación Nuevo Arco Iris (2007). Los caminos de alianza entre políticos y partidos. Bogotá: Corporación Nuevo Arcoíris. Recuperado de https://colectivodeabogados.org/IMG/pdf/Informe_final_para_pol_tica.pdf

Corpovisionarios (2017). Tejiendo acciones de paz. Bogotá: Corpovisionarios. Recuperado de https://www.researchgate.net/profile/Juan_Pino_Uribe/publication/317007506_Tejiendo_acciones_de_paz_Informe_final/ links/591dfb4345851540595d92e6/Tejiendo-acciones-de-paz-Informe-final.pdf

Cruz Rodríguez, E. (2015). El éxito relativo de la política de paz en Colombia. Revista San Gregorio, 1(9), 34-41.

Dávila Ladrón de Guevara, A. (2002). Democracia pactada: el Frente Nacional y el proceso constituyente de 1991 en Colombia. Bogotá: Alfaomega.

Dávila Ladrón de Guevara, A. y Salgado, N. (2002). La metamorfosis del clientelismo. En F. Gutiérrez Sanín (comp.), Degradación o cambio: evolución del sistema político colombiano (pp. 319-356). Bogotá: Norma.

Deas, M. y Gaitán Daza, F. (1995). Dos ensayos especulativos sobre la violencia en Colombia. Bogotá: Tercer Mundo.

Díaz, A. (2006). Las encuestas y la reelección. Colombia Contexto, 11(1), 1-5.

Duddley, S. (2008). Armas y urnas: historia de un genocidio político. Bogotá: Planeta.

Duncan, G. (2007). Los señores de la guerra: de paramilitares, mafiosos y autodefensas en Colombia. Bogotá: Planeta.

Duncan, G. (2009). El dinero no lo es todo: acerca del narcotráfico en la persistencia del conflicto colombiano. En Á. Camacho, G. Duncan, C. Steiner, R. Vargas y M. E. Wills (eds.), A la sombra de la guerra: ilegalidad y nuevos órdenes regionales en Colombia (pp. 165-213). Bogotá: Universidad de los Andes.

Eaton, K. (2006). The downside of decentralization: Armed clientelism in Colombia. Security Studies, 15(4), 533-562. 
Eaton, K. y Prieto, J. D. (2017). Subnational authoritarianism in Colombia: Divergent paths in Cesar and Magdalena. En T. Hilgers y L. Macdonald (eds.), Violence in Latin America and the caribbean subnational structures, institutions, and clientelistic networks. Cambridge: Cambridge University Press.

Echeverry, C. y Ortega, B. A. (2012). Reseña del libro Democracias precarias. Trayectorias políticas divergentes en Colombia y Venezuela de Ana María Bejarano. Colombia Internacional, 75, 174-178. http://dx.doi.org/10.7440/colombint75.2012.05

Echandía Castila, C. (1999). Geografía del conflicto armado y las manifestaciones de la violencia en Colombia. Bogotá: Vicepresidencia de la República.

El País (2013, agosto 15). "La idea es cambiar las armas por votos": presidente Santos. Recuperado de http://www.elpais.com.co/judicial/la-idea-es-cambiar-lasarmas-por-votos-presidente-santos.html

Falleti, T. G. (2010). Decentralization and subnational politics in Latin America. Nueva York: Cambridge University Press.

Fernández de Lara Gaitán, A. E. (2016). Acceso a la información pública en América Latina: análisis de su diseño institucional en Chile, Colombia y México (20022014). Revista Debates, 1O(1), 111. https://doi.org/10.22456/1982-5269.62629

Franco, V. L. (2003). Violencias, conflictos urbanos y guerra civil: el caso de la ciudad de Medellín en la década de los noventa. En J. W. Balbín Álvarez (ed.), Violencias y conflictos urbanos: un reto para las políticas públicas (pp. 59-110). Medellín, Colombia: Instituto Popular de Capacitación.

Franco, V. L. (2005). Prácticas hegemónicas de la coalición políticamente dominante en Medellín y su entorno urbano-regional. Estudios Políticos, 26, 151-182.

Franco, V. L. (2007). La justificación normativa de la guerra civil. Estudios Políticos, $30,13-44$.

Garay Salamanca, L. J. (dir.) (2008). La captura y reconfiguración cooptada del Estado en Colombia. Bogotá: Fundación Método.

García Sánchez, M. (2007). Sobre balas y votos: violencia política y participación electoral en Colombia, 1990-1994. En D. Hoyos Gómez (ed.), Entre la persistencia y el cambio: reconfiguración del escenario partidista y electoral en Colombia (pp. 84-117). Bogotá: Universidad del Rosario.

García, M. (2009). Political violence and electoral democracy in Colombia. Participation and voting behavior in violent contexts (Tesis de doctorado). University of Pittsburgh. 
García, M. y Hoskin, G. (2003). Political participation and war in Colombia: An analysis of the 2002 elections. Working Paper, 38.

Gómez-Albarello, J. G. y Rodríguez-Raga, J. C. (2007). Competencia electoral en grandes circunscripciones: el caso del Senado colombiano. En D. Hoyos Gómez (ed.), Entre la persistencia y el cambio: reconfiguración del escenario partidista y electoral en Colombia (pp. 49-83). Bogotá: Universidad del Rosario.

Gomis Balestreri, M., Amaya Panche, J. y Romero Vidal, M. (2016). El síndrome del tirano silencioso: del Estado fantasma al autoritarismo extractivista local. Estudio de caso: el Meta, Colombia. En J. Olguín Olate (coord.), Estados autoritarios latinoamericanos: ayer, hoy y proyecciones (pp. 59-103). Santiago de Chile: Universidad Central de Chile.

González, F. E. (2003). ¿Colapso parcial o presencia diferenciada del Estado en Colombia? Una mirada desde la historia. Colombia Internacional, 58, 124-157.

González, F. E., Bolívar, I. J. y Vázquez, T. (2003). Violencia política en Colombia: de la nación fragmentada a la construcción del Estado. Bogotá: Centro de Investigación y Educación Popular.

Gutiérrez Sanín, F. (2004). Criminales y rebeldes: una discusión de la economía política del conflicto armado desde el caso colombiano. Estudios Políticos, 24, 37-71.

Gutiérrez Sanín, F. (2007). ¿Lo que el viento se llevó? Los partidos políticos y la democracia en Colombia, 1958-2002. Bogotá: Norma.

Gutiérrez Sanín, F. (2010). Reflexiones a propósito del libro Yrefundaron la patria. En C. López Hernández (ed.), Y refundaron la patria...: de cómo mafiosos y políticos reconfiguraron el Estado colombiano (pp. 9-28). Bogotá: Debate.

Gutiérrez Sanín, F. y Barón, M. (2005) Re-stating the state: Paramilitary territorial control and political order in Colombia (1978-2004). Working Paper, 66.

Hartlyn, J. (1993). La política del régimen de coalición: la experiencia del Frente Nacional en Colombia. Bogotá: Tercer Mundo.

Higuera Mendieta, I. (2017). Control armado y comportamiento electoral: un cuasiexperimento en el Caguán. Documentos de Trabajo sobre Economía Regional, 256.

Hoyos Gómez, D. (2009). Dinámicas político-electorales en zonas de influencia paramilitar: análisis de la competencia y la participación electoral. Análisis Político, 22(65), 13-32.

Jiménez Peña, G. (2014). Multinational corporations and corporate social responsibility in the peace building in Colombia. Cuadernos de Administración, 27(48), 67-96. 
Kalyvas, S. (2004). La ontología de la violencia política: acción e identidad en las guerras civiles. Análisis Político, 52, 51-76.

Kline, H. (1995). Colombia: Democracy under assault. Boulder: Westview.

Leal Buitrago, F. (2010). La crisis del régimen bipartidista. En L. J. Orjuela (comp.), El Estado en Colombia (pp. 67-102). Bogotá: Universidad de los Andes.

Leal Buitrago, F. y Dávila Ladrón de Guevara, A. (1991). Clientelismo: el sistema político y su expresión regional. Bogotá: Universidad Nacional de Colombia.

Leal Buitrago, F. y Zamosc, L. (eds.) (1990). Al filo del caos: crisis política en la Colombia de los años 8o. Bogotá: Tercer Mundo.

Leiteritz, R., Nasi, C. y Rettberg, A. (2009). Para desvincular los recursos naturales del conflicto armado en Colombia: recomendaciones para formuladores de política y activistas. Colombia Internacional, 70, 215-229.

López Hernández, C. (2010). La refundación de la patria: de la teoría a la evidencia. En C. López Hernández (ed.), Y refundaron la patria...: de cómo mafiosos y políticos reconfiguraron el Estado colombiano (pp. 29-78). Bogotá: Debate.

Losada, R. y Liendo, N. (2016). El partido Centro Democrático en Colombia: razones de su surgimiento y éxito. Análisis Político, 29(87), 41-59.

Nasi, C. (2007). Cuando callan los fusiles: impacto de la paz negociada en Colombia y Centroamérica. Bogotá: Norma.

Nasi, C. y Rettberg, A. (2005). Los estudios sobre conflicto armado y paz: un campo en evolución permanente. Colombia Internacional, 62, 64-85.

Norza, E. y Espino, G. (2011). Criminalidad y análisis espacial de los delitos en Colombia, 2010. Revista Criminalidad, 53(1), 17-43.

Norza, E. y Espino, G. (2011). Criminalidad y análisis espacial de los delitos en Colombia, 2010. Revista Criminalidad, 53(1), 17-43.

Milanese, J. P., Abadía, A. A. y Manfredi, L. (2016). Elecciones regionales en Colombia 2015: análisis de las nuevas gobernaciones y asambleas departamentales. Revista Uruguaya de Ciencia Política, 25(1), 1-26.

Montoya, A. M. (2014). Opinión pública colombiana sobre las FARC como partido político. En Perspectivas desde el Barómetro de las Américas: 2014. Nashville: LAPOP.

Orjuela Escobar, L. J. (2000). La debilidad del estado colombiano en tiempos del neoliberalismo y el conflicto armado. Colombia Internacional, 49-50, 103-116. 
Orjuela Escobar, L. J. (comp.) (2010). El Estado en Colombia. Bogotá: Universidad de los Andes.

Palacios, M. (1995). Entre la legitimidad y la violencia: Colombia 1875-1994. Bogotá: Norma.

Palacios, M. (2002). La fragmentación regional de las clases dominantes en Colombia: una perspectiva histórica. En La clase más ruidosa y otros ensayos sobre política e historia (pp. 1663-1689). Bogotá: Norma.

Palacios Luna, J. M. (2016). Confianza institucional, corrupción e inversión pública en Colombia. Ponencia presentada en International Congress of the Latin American Studies, Lima, Perú.

Pécaut, D. (2001a). Guerra contra la sociedad. Bogotá: Espasa.

Pecáut, D. (2001b). Orden y violencia: evolución sociopolítica de Colombia entre 1930 y 1953. Bogotá: Norma.

Peñate, A. (1999). El sendero estratégico del ELN: del idealismo guevarista al clientelismo armado. En M. V. Llorente y M. D. Deas (comps.), Reconocer la guerra para construir la paz (pp. 53-98). Bogotá: Norma.

Pino Uribe, J. F. (2013). Régimen y territorio: trayectorias de desarrollo del régimen político a nivel subnacional en Colombia 1988-2011. Documentos de trabajo, 23.

Pino Uribe, J. F. (2016). Elecciones 2015 y posconflicto: posibilidades y retos de la implementación de los acuerdos de paz en los municipios del Programa de Consolidación Territorial. En F. Barreto (ed.), Elecciones regionales 2015: los retos de un país en camino hacia la paz (pp. 341-373). Bogotá: Konrad Adenauer Stiftung.

Pino Uribe, J. F. (2017). Entre democracias y autoritarismos: una mirada crítica al estudio de la democracia subnacional en Colombia y Latinoamérica. Colombia Internacional, 91, 215-242. https://doi.org/10.7440/colombiaint91.2017.07

Pizarro Leongómez, E. (1989). Democracia restringida y desinstitucionalización política. En P. Medellín (ed.), La reforma del Estado en América Latina (pp. 280-334). Bogotá: Friedrich Ebert Stiftung.

Pizarro Leongómez, E. (1991). Las FARC (1949-1966): de la autodefensa a la combinación de todas las formas de lucha. Bogotá: Universidad Nacional de Colombia.

Pizarro Leongómez, E. (2006). Las FARC-EP: ¿̇repliegue estratégico, debilitamiento o punto de inflexión? En F. Gutiérrez Sanín y M. E. Wills (eds.), Nuestra guerra sin nombre: transformaciones del conflicto en Colombia (pp. 171-207). Bogotá: Norma. 
Pizarro Leongómez, E. y Bejarano, A. M. (2003). Colombia: A failed state? Revista: Harvard Review of Latin America, 2(3).

Querejazu, A. (2011). Gobernanza global y Estado: desterritorialización y desvanecimiento de la autoridad. En H. J. Godoy, R. González Arana y G. Orozco Restrepo (eds.), Construyendo lo global: aportes al debate de relaciones internacionales (pp. 35-59). Barranquilla, Colombia: Universidad del Norte.

Quishpe, R. (2017). Reenfocando la reintegración política: Perspectivas Investigativas para Colombia (Refocusing Political Reintegration: Research Perspectives for Colombia). SSRN Electronic Journal. https://doi.org/10.2139/ssrn.3063823

Ramírez, W. (2005). Autodefensas y poder local. En A. Rangel (ed.), El poder paramilitar (pp. 137-204). Bogotá: Fundación Seguridad y Democracia.

Rangel, A. (1997). El poder local: objetivo actual de la guerrilla. En Descentralización y orden público (pp. 38-68). Bogotá: Nuevo Milenio.

Rangel, A., Borrero, A. y Ramírez, W. (2004). Conflictividad territorial en Colombia. Bogotá: Escuela Superior de Administración Pública.

Rettberg, A., Leiteritz, R. y Nasi, C. (2010). Entrepreneurial activity and civil war in Colombia: Exploring the mutual determinants between armed conflict and the private sector. Helsinki: WIDER. Recuperado de https://www.econstor. $\mathrm{eu} / \mathrm{handle} / 10419 / 54120$

Rettberg, A. y Ortiz Riomalo, J. F. (2014). Golden conflict: Exploring the relationship between gold mining, armed conflict, and criminality in Colombia. Electronic Journal, 41. http://dx.doi.org/10.2139/ssrn.2418883

Restrepo Botero, D. I. (2015). Procesos de descentralización en Bolivia y Colombia, 1980-2005: una propuesta de economía política espacial comparada. Bogotá: Universidad Nacional de Colombia.

Romero, M. (2003). Paramilitares y Autodefensas 1982-2003. Bogotá: Planeta.

Romero, M. (2007). Parapolítica la ruta de la expansión paramilitar y los acuerdos políticos. Bogotá: Intermedio.

Romero, M., Valencia, L. y Alonso, M. A. (2007). Parapolítica: la ruta de la expansión paramilitar y los acuerdos políticos. Bogotá: Corporación Nuevo Arco Iris.

Rubio, M. (1998). Rebeldes y criminales: una crítica a la tradicional distinción entre el delito político y el delito común. En J. Arocha, F. Cubides y M. Jimeno (eds.), Las violencias: inclusión creciente (pp. 121-185). Bogotá: Universidad de los Andes. 
Rubio, M. (1999). Violencia y conflicto en los noventa. Coyuntura Social, 22.

Rubio, M. (2002). Conflicto y finanzas públicas municipales. Documento CEDE, 17.

Rubio, M. (2005). Illegal armed groups and local politics in Colombia. Journal of Drug Issues, 35(1), 107-130.

Sánchez, F. y Chacón, M. (2005). Conflicto, Estado y descentralización: del progreso social a la disputa armada por el control local. Documento CEDE, 33.

Sánchez, G. (1991). Guerra y política en la sociedad colombiana. Bogotá: Punto de Lectura.

Stathis, K. (2001). La violencia en medio de la guerra civil: esbozo de una teoría. Análisis Político, 42.

Valencia, L. (2009). Municipio y violencia paramilitar en colombia 1984-2008. En F. Velásquez C. y J. Zuluaga Nieto (eds.), Las otras caras del poder: territorio, conflicto y gestión pública en municipios colombianos (pp. 141-178). Bogotá: Foro Nacional por Colombia.

Valencia Villa, H. (1987). Cartas de batalla: una crítica del constitucionalismo colombiano. Bogotá: Universidad Nacional de Colombia.

Velásquez, F. (2009). Las otras caras del poder: territorio, conflicto y gestión pública en municipios colombianos. Bogotá: Foro Nacional Ambiental.

Wills, M. E. y Rivera, M. M. (2009). Poder, familia y clientelismos en Montería, Córdoba (1950-2008): visibilización y ascenso de las mujeres en contextos totalitarios. En Á. Camacho, G. Duncan, C. Steiner, R. Vargas y M. E. Wills (eds.), A la sombra de la guerra: ilegalidad y nuevos órdenes regionales en Colombia (pp. 97-165). Bogotá: Universidad de los Andes. 
